\title{
Numerical Simulation on the Thermal and Hydraulic Behaviors of Batch Pipelining Crude Oils with Different Inlet Temperatures
}

\author{
K. Wang' , J.J. Zhang ${ }^{1 *}$, B. Yu', J. Zhou' ${ }^{1}$, J.H. Qian' ${ }^{2}$ and D.P. Qiu² \\ 1 Beijing Key Laboratory of Urban Oil and Gas Distribution Technology, China University of Petroleum (Beijing), Beijing, 102249 - P.R. China \\ 2 SINOPEC Pipeline Co., Xuzhou, Jiangsu, 221008 - P.R. China \\ e-mail:wang163kai163@163.com-zhangij@cup.edu.cn-yubobox@yahoo.com.cn-zixx-004124@163.com \\ qianih@gdcygs.com - qiudp@gdcygs.com \\ * Corresponding author
}

Résumé - Simulations numériques sur les règles thermiques et hydrauliques du transport discontinu par pipeline du pétrole brut à différentes températures d'entrée - Un modèle instable hydraulique et thermodynamique est utilisé pour décrire les caractéristiques de la conduction de la chaleur et de l'écoulement du fluide dans le transport discontinu par pipeline enterré du pétrole brut à différentes températures d'entrée; la méthode du contrôle de volume, combinée à la méthode de la différence finie, est employée pour discrétiser les équations de contrôle. Le modèle numérique et le code d'ordinateur sont vérifiés à travers les données des tests sur le terrain d'un pipeline en Chine; le résultat des simulations est conforme au résultat des essais. Les changements périodiques de la densité du flux de chaleur, de la température du pétrole, du stockage thermique du sol et de la perte par frottement sont présentés et expliqués, et la relation de couplage entre eux est clarifiée. Pour le transport alternatif de deux sortes de pétrole brut, trois plans de chauffage sont proposés, leurs économie et sécurité sont déjà évaluées. Les résultats des simulations montrent que le plan de chauffage le moins coûteux en énergie est celui dans lequel seule une petite portion de pétrole à bas point d'écoulement, qui se déplace juste avant le pétrole à point d'écoulement élevé, est chauffée à la même température que ce dernier.

\footnotetext{
Abstract - Numerical Simulation on the Thermal and Hydraulic Behaviors of Batch Pipelining Crude Oils with Different Inlet Temperatures - An unsteady hydraulic and thermodynamic model is proposed to describe the heat and fluid flow characteristics of batch pipelining of crude oils in buried pipeline with different inlet temperatures, and the control volume method combined with finite difference method is used to discretize the governing equations. The numerical model and computer code are verified by field test data of a pipeline in China, and the resulting simulations are in good agreement with experiments. The periodic behaviors of heat flux density, oil temperature, heat storage of soil and friction loss are presented and explained, and the strong coupling relations within them are clarified. For two kinds of crude oils transported in batches, three heating schemes are proposed and the economy and safety are evaluated. The simulation results show that the heating scheme, in which only a small portion of the low-pour-point crude oil just traveling before the high-pour-point crude oil is heated and all the high-pour-point crude oil is heated to a uniform temperature, costs the smallest heating energy.
} 


\section{NOMENCLATURE}

A Cross-section area of the pipeline $\left(\mathrm{m}^{2}\right)$

$c_{1} \quad$ Fitting coefficient $(\mathrm{Pa} \cdot \mathrm{s})$

$c_{2} \quad$ Fitting coefficient $\left({ }^{\circ} \mathrm{C}^{-1}\right)$

$C_{k} \quad$ Heat capacity of the $k$ th layer, including wax deposition layer, pipe wall and corrosion protection coating $\left(\mathrm{J} /\left(\mathrm{kg} \cdot{ }^{\circ} \mathrm{C}\right)\right)$

$C_{p}$ Heat capacity under constant pressure of the crude oil $\left(\mathrm{J} /\left(\mathrm{kg} \cdot{ }^{\circ} \mathrm{C}\right)\right)$

$C_{s} \quad$ Heat capacity of the soil $\left(\mathrm{J} /\left(\mathrm{kg} \cdot{ }^{\circ} \mathrm{C}\right)\right)$

$D$ Inner diameter of the wax deposition layer (m)

$f \quad$ Darcy friction coefficient

$g$ Gravity acceleration $\left(\mathrm{m} / \mathrm{s}^{2}\right)$

Gr Grashof number under the average temperature of the crude oil

$h \quad$ Specific enthalpy of the crude oil $(\mathrm{J} / \mathrm{kg})$

$H$ Frictional loss (MPa)

$H_{0} \quad$ Buried depth of the pipeline (m)

$H_{c}$ Depth of the computational domain of the soil (m)

$L \quad$ Half width of the computational domain of the soil (m)

$N \quad$ Point number of the pipeline

$\mathrm{Nu}$ Nusselt number under the average temperature of the crude oil

$P \quad$ Average pressure on the pipeline cross-section $(\mathrm{Pa})$

$\mathrm{Pr}$ Prandtl number under the average temperature of the crude oil

$\operatorname{Pr}_{w}$ Prandtl number under the inner wall temperature of the wax deposition layer

$q$ Heat flux density from the crude to the surroundings $\left(\mathrm{W} / \mathrm{m}^{2}\right)$

$q_{1}$ Heat flux lost or absorbed by the crude oils per unit length $(\mathrm{W} / \mathrm{m})$

$Q_{H}$ Energy consumed by heating crude oils (GJ)

$Q_{s} \quad$ Heat storage of soil per unit length $(\mathrm{GJ} / \mathrm{m})$

$r \quad$ Radial direction (m)

$R_{0} \quad$ Inner radius of the wax deposition layer (m)

$R_{k}$ Outer radius of the $k$ th layer, including wax deposition layer, pipe wall and corrosion protection coating $(\mathrm{m})$

Re Reynold number under the average temperature of the crude oil

$s \quad$ Height difference of the axial direction of the pipeline $(\mathrm{m})$

$t$ Time (s)

$T$ Temperature of the crude oil $\left({ }^{\circ} \mathrm{C}\right)$

$T_{0} \quad$ Inner wall temperature of the wax deposition layer $\left({ }^{\circ} \mathrm{C}\right)$

$T_{a} \quad$ Air temperature $\left({ }^{\circ} \mathrm{C}\right)$

$T_{c} \quad$ Temperature of the constant temperature layer $\left({ }^{\circ} \mathrm{C}\right)$

$T_{i} \quad$ Temperature of the crude oil at Point $i$ at present time step $\left({ }^{\circ} \mathrm{C}\right)$

$T_{\text {inlet }}$ Inlet temperature of the crude oil $\left({ }^{\circ} \mathrm{C}\right)$
$T_{k} \quad$ Temperature of the $k$ th layer, including wax deposition layer, pipe wall and corrosion protection coating $\left({ }^{\circ} \mathrm{C}\right)$

$T_{n} \quad$ Normal temperatures of the crude oil $\left({ }^{\circ} \mathrm{C}\right)$

$T_{p} \quad$ Pour point of the crude oil $\left({ }^{\circ} \mathrm{C}\right)$

$T_{s} \quad$ Soil temperature $\left({ }^{\circ} \mathrm{C}\right)$

$u \quad$ Specific energy of the crude oil $(\mathrm{J} / \mathrm{kg})$

$v \quad$ Specific volume of the crude oil $\left(\mathrm{m}^{3} / \mathrm{kg}\right)$

$V \quad$ Average velocity of the crude oil $(\mathrm{m} / \mathrm{s})$

$V_{a}$ Average velocity of the wind $(\mathrm{m} / \mathrm{s})$

$x$ Horizontal direction (m)

$y \quad$ Vertical direction $(\mathrm{m})$

$z \quad$ Axial direction of the pipeline (m)

$Z$ Pipeline length from the outlet of the pumping station to the inlet of the next pumping station $(\mathrm{km})$

$\alpha$ Angle between the axis of the pipeline and the horizontal line

$\alpha_{0}$ Heat transfer coefficient of the oil stream at the wax deposition layer $\left(\mathrm{W} /\left(\mathrm{m}^{2 .}{ }^{\circ} \mathrm{C}\right)\right)$

$\alpha_{a}$ Heat transfer coefficient at the ground surface $\left(\mathrm{W} /\left(\mathrm{m}^{\left.2 \cdot{ }^{\circ} \mathrm{C}\right)}\right)\right.$

$\beta \quad$ Expansion coefficient of the crude oil $\left(\mathrm{K}^{-1}\right)$

$\eta \quad$ Dynamic viscosity of the crude oil $(\mathrm{Pa} \cdot \mathrm{s})$

$\lambda$ Thermal conductivity of the crude oil $\left(\mathrm{W} /\left(\mathrm{m} \cdot{ }^{\circ} \mathrm{C}\right)\right)$

$\lambda_{k}$ Thermal conductivity of the $k$ th layer, including wax deposition layer, pipe wall and corrosion protection coating $\left(\mathrm{W} /\left(\mathrm{m}^{\circ}{ }^{\circ} \mathrm{C}\right)\right)$

$\lambda_{s}$ Thermal conductivity of the soil $\left(\mathrm{W} /\left(\mathrm{m}^{\circ}{ }^{\circ} \mathrm{C}\right)\right)$

$\theta \quad$ Circumferential direction

$\rho \quad$ Density of the crude oil $\left(\mathrm{kg} / \mathrm{m}^{3}\right)$

$\rho_{15}$ Density of the crude oil at $15^{\circ} \mathrm{C}\left(\mathrm{kg} / \mathrm{m}^{3}\right)$

$\rho_{20}$ Density of the crude oil at $20^{\circ} \mathrm{C}\left(\mathrm{kg} / \mathrm{m}^{3}\right)$

$\rho_{k} \quad$ Density of the $k$ th layer, including wax deposition layer, pipe wall and corrosion protection coating $\left(\mathrm{kg} / \mathrm{m}^{3}\right)$

$\rho_{s} \quad$ Soil density $\left(\mathrm{kg} / \mathrm{m}^{3}\right)$

$\zeta$ Temperature coefficient $\left(\mathrm{kg} /\left(\mathrm{m}^{3 .}{ }^{\circ} \mathrm{C}\right)\right)$

\section{INTRODUCTION}

For long distance transport of crude oil pipelining is an economical method and widely adopted in petroleum industry. Crude oils with high viscosity and/or high-pourpoint need to be heated before being pumped into the pipeline for safety operation, while crude oils with low viscosity and/or low-pour-point can be transported at normal temperature. The transport with heating and without heating requires different operation techniques. It is easy to come to that different kinds of crude oils can be blended and transported with a single transport technique. However, the blend of crude oils with different grades may have adverse impacts on the refining process and quality of the refined products. Therefore, it is necessary 
to transport and store different crude oils separately to satisfy the demand of petrochemical industry, and it is likely to encounter batch pipelining of crude oils with different inlet temperatures, during which the heat transfer coupling with hydraulics should be studied carefully.

In 1999, batch pipelining of crude oils both with heating and without heating transport technique was first applied in the U.S. Pacific Pipeline System [1] due to the demand of petroleum industry. It was reported that batch pipelining of five kinds of crude oils was achieved with the oil inlet temperatures ranging from 18 to $80^{\circ} \mathrm{C}$, but unfortunately little technique reports are available. In recent years some studies have been carried out in our research group to find out the thermal and hydraulic behaviors of batch pipelining of crude oils [2-4]. Cui, Fan and Yao studied some thermal and hydraulic periodic characteristics, but they rarely systematically and comprehensively analyzed the periodic behaviors and the economy and safety of the new transport technique have never been evaluated. The present paper is a comprehensive report on the thermal and hydraulic behaviors. In addition, evaluation on economy and safety of the new technique is performed for the first time.

\section{MODELING}

Oil pipeline buried in soil is sketched in Figure 1a. Batch pipelining of crude oils with different inlet temperatures in buried pipeline involves a complex heat transfer and hydraulic coupling process. To simplify the calculation and get a solution satisfying the requirement of engineering application, some assumptions are made in the computer modeling:

- the oil temperature across the cross-section of a pipe is assumed to be uniform, that is to say, the oil temperature is only a function of time and axial position;

- the soil is homogeneous and the properties of soil such as thermal conductivity, density, thermal capacity and others do not change in space;

- the mixture between two batches of crude oils is ignored, in other words, the proceeding crude is pushed by the subsequent crude like a rigid drive;

- the volumetric flow rate is constant along the pipeline;

- actually, the heat conduction of the soil outside the pipe is a three dimensional problem. Considering that soil temperature is influenced mainly by oil temperature, the temperature gradient in the $z$ direction is quite small compared with the $x$ and $y$ directions. Therefore the influence of heat conduction in the $z$ direction can be neglected for it can simplify the three dimensional problem to two dimensional, which remarkably enhances the computing efficiency;

- The thermal-influenced region of the pipeline is within 10 meters, which means that beyond 10 meters from the pipeline the soil temperature is not affected by the pipeline. This has been demonstrated by both experimental data and numerical analysis [5]. Due to this simplification, a finite soil domain is studied in the numerical simulation as shown in Figure 1b.

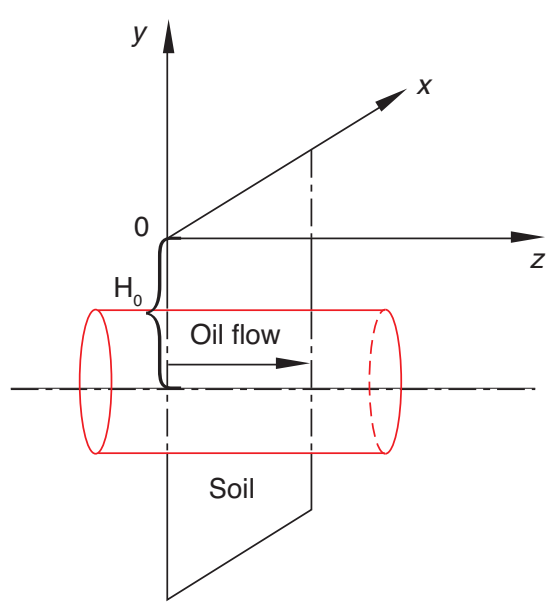

a) Sketch of a buried pipeline

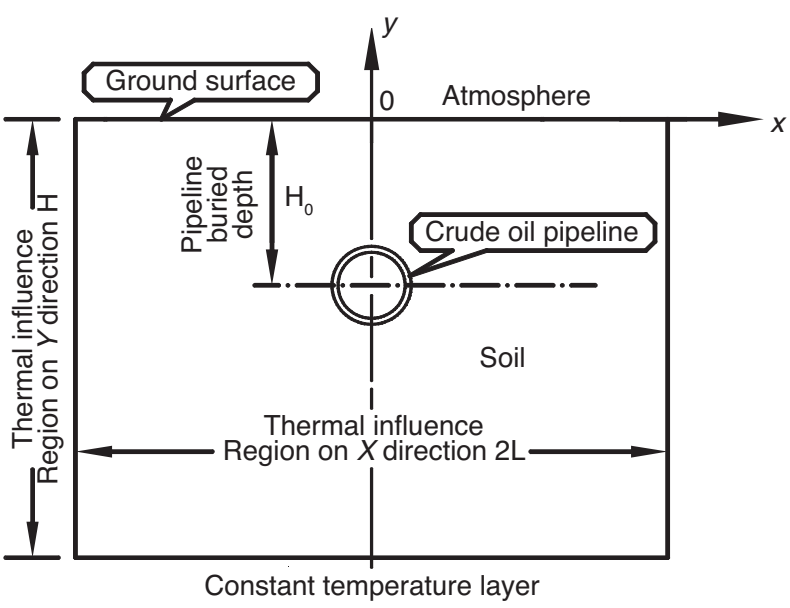

b) Cross section of the pipeline

Figure 1

Sketch map of the buried pipeline. 
Based on the above assumptions and simplifications, a mathematical model describing the thermal system of a buried hot-oil-pipeline is obtained as follows, which includes the equations for oil stream, heat conduction equations of the wax deposition layer, pipe wall and corrosion protection coating and heat conduction equation of the soil. The mass conservation equation, momentum conservation equation and energy conservation equation of the oil stream can be derived and written as follows [6].

$$
\begin{gathered}
\frac{\partial}{\partial t}(\rho A)+\frac{\partial}{\partial z}(\rho V A)=0 \\
\frac{\partial V}{\partial t}+V \frac{\partial V}{\partial z}=-g \sin \alpha-\frac{1}{\rho} \frac{\partial p}{\partial z}-\frac{f}{D} \frac{V^{2}}{2} \\
\frac{\partial}{\partial t}\left[(\rho A)\left(u+\frac{V^{2}}{2}+g s\right)\right]+\frac{\partial}{\partial z}\left[(\rho V A)\left(h+\frac{V^{2}}{2}+g s\right)\right]=-\pi D q
\end{gathered}
$$

The heat transfer equation [6] of the oil stream can be deduced from Equation (1) - Equation (3), as shown in Appendix 1.

$$
C_{p} \frac{\mathrm{d} T}{\mathrm{~d} t}-\frac{T+273.15}{\rho} \beta \frac{\mathrm{d} p}{\mathrm{~d} t}-\frac{f V^{3}}{2 D}=-\frac{4 q}{\rho D}
$$

The heat conduction equations of the wax deposition layer, pipe wall and corrosion protection coating are listed below [7].

$$
\rho_{k} C_{k} \frac{\partial T_{k}}{\partial t}=\frac{1}{r} \frac{\partial}{\partial r}\left(\lambda_{k} r \frac{\partial T_{k}}{\partial r}\right)+\frac{1}{r^{2}} \frac{\partial}{\partial \theta}\left(\lambda_{k} \frac{\partial T_{k}}{\partial \theta}\right)
$$

where $k=1,2,3$ stands for the wax deposition layer, pipe wall and corrosion protection coating respectively.

The heat conduction equation of the soil is as follows [7]:

$$
\rho_{s} C_{s} \frac{\partial T_{s}}{\partial t}=\frac{\partial}{\partial x}\left(\lambda_{s} \frac{\partial T_{s}}{\partial x}\right)+\frac{\partial}{\partial y}\left(\lambda_{s} \frac{\partial T_{s}}{\partial y}\right)
$$

The heat transfer of the oil stream, wax deposition layer, pipe wall, corrosion protection coating and the soil have effects on each other, which can be described as following equations [8]:

$$
\begin{gathered}
-\left.\lambda_{1} \frac{\partial T_{1}}{\partial r}\right|_{r=R_{0}}=\alpha_{0}\left(T-T_{0}\right) \\
\left.\lambda_{k} \frac{\partial T_{k}}{\partial r}\right|_{r=R_{k}}=\left.\lambda_{k+1} \frac{\partial T_{k+1}}{\partial r}\right|_{r=R_{k}} \quad k=1,2 \\
\left.T_{k}\right|_{r=R_{k}}=\left.T_{k+1}\right|_{r=R_{k}} \quad k=1,2 \\
\left.\lambda_{3} \frac{\partial T_{3}}{\partial r}\right|_{r=R_{3}}=\left.\lambda_{s} \frac{\partial T_{s}}{\partial r}\right|_{r=R_{3}} \\
\left.T_{3}\right|_{r=R_{3}}=\left.T_{s}\right|_{r=R_{3}}
\end{gathered}
$$

$\alpha_{0}$ can be solved by the following equations [8]:

$$
R e=\frac{V D \rho}{\eta}
$$

$$
\begin{gathered}
N u=\frac{\alpha_{0} D}{\lambda} \\
\operatorname{Pr}=\frac{\eta C_{p}}{\lambda} \\
G r=D^{3} g \beta\left(T-T_{0}\right)\left(\frac{\rho}{\eta}\right)^{2}
\end{gathered}
$$

- $\operatorname{Re}<2000$ and $G r \cdot \operatorname{Pr}>5 \times 10^{2}$

$$
N u=0.17 \operatorname{Re}^{0.33} \operatorname{Pr}^{0.43} G r^{0.1}\left(\frac{P r}{P r_{w}}\right)^{0.25}
$$

- $\operatorname{Re}>10^{4}$ and $\operatorname{Pr}<2500$

$$
\alpha_{0}=0.021 \frac{\lambda}{D} \operatorname{Re}^{0.8} \operatorname{Pr}^{0.44}\left(\frac{P r}{P r_{w}}\right)^{0.25}
$$

- $2000 \leq \operatorname{Re} \leq 10^{4}$

$$
N u=K_{0} \operatorname{Pr}^{0.43} G r^{0.1}\left(\frac{P r}{P r_{w}}\right)^{0.25}
$$

where $K_{0}$ is the function of $R e$, and their relation is shown in Table 1.

TABLE 1

The function relation between $R e$ and $K_{0}$

\begin{tabular}{c|c|c|c|c|c|c|c|c|c|c|c|c}
\hline$R e \times 10^{-3}$ & 2.2 & 2.3 & 2.5 & 3.0 & 3.5 & 4.0 & 5.0 & 6.0 & 7.0 & 8.0 & 9.0 & 10 \\
\hline$K_{0}$ & 1.9 & 3.2 & 4.0 & 6.8 & 9.5 & 11 & 16 & 19 & 24 & 27 & 30 & 33 \\
\hline
\end{tabular}

Only the right part of the calculation domain is taken into consideration due to the symmetry. The boundary conditions are written below [8].

$$
\begin{gathered}
\lambda_{s} \frac{\partial T_{s}}{\partial x}=0, \text { at } x=0,0 \leq|y| \leq H_{0}-R_{3} \\
\lambda_{s} \frac{\partial T_{s}}{\partial x}=0, \text { at } x=0, H_{0}+R_{3} \leq|y| \leq H \\
\frac{\partial T_{s}}{\partial y}=\frac{\alpha_{a}}{\lambda_{s}}\left(T_{a}-T_{s}\right), \text { at } y=0 \\
\alpha_{a}=13.6+7.0 \sqrt{V_{a}} \\
\frac{\partial T_{s}}{\partial x}=0, \text { at }|x|=L \\
T_{s}=T_{c}, \text { at }|y|=H_{c} \\
T(1)=T_{\text {inlet }}(t)
\end{gathered}
$$

Oil prosperities are given as:

$$
\rho=\rho_{20}-\zeta(T-20)
$$




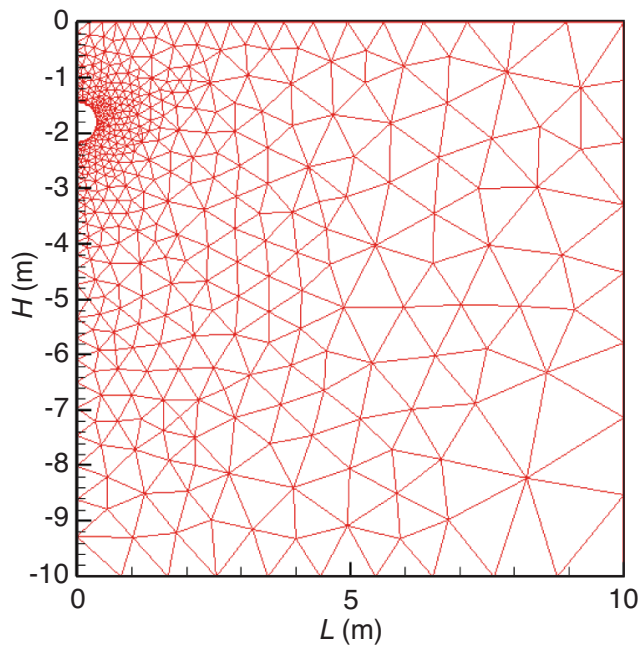

a) Triangular grids of soil region

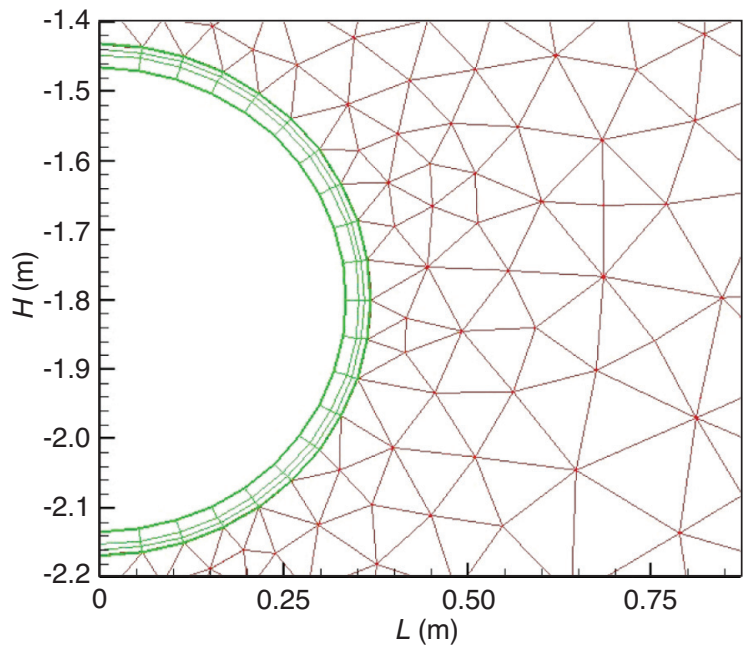

b) Structured polar grids and the enlarged view of the unstructured grids near the pipe

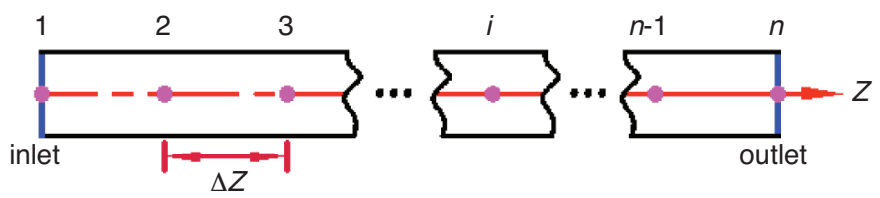

c) Computational nodes of the pipeline

Figure 2

Computation domain and grid generation.

$$
\begin{gathered}
\zeta=1.825-0.001315 \rho_{20} \\
c_{p}=\frac{1}{\sqrt{\rho_{15} / 1000}}(1687+3.39 T) \\
\lambda=\frac{0.137}{\sqrt{\rho_{15} / 1000}}\left(1-0.54 \times 10^{-3} T\right) \\
\eta=c_{1} e^{c_{2} \times T}
\end{gathered}
$$

where the temperature scale used is ' ${ }^{\circ} \mathrm{C}$ '.

It should be pointed out that the computed result of the model is quasi-steady solution and independent of the initial condition. Therefore, initial conditions can be arbitrary assignment.

\section{NUMERICAL METHOD AND VALIDATION OF THE COMPUTER CODE}

A Delaunay triangulation method [9] is used to generate the grids of the soil domain automatically, with which unstructured triangular grids in a Cartesian coordinate system are generated as showed in Figure 2a. Since the temperature gradient is larger in the region near the pipe, denser meshes are generated in the region close to the pipeline. A structural grid generation in the polar coordinate system is applied to the steel pipe wall, wax deposition layer and corrosion protection coating. Figure $2 b$ shows the annular meshes in the polar coordinate system. Uniform grids are used for spatial discretization of the pipeline as shown in Figure 2c. A finite difference method (FDM) is used to discretize the oil stream equation while a control volume method (CVM) is employed to discretize the governing equations of the wax deposition layer, pipe wall, corrosion protection coating and soil and their boundary conditions. The discretization procedures [10] in details are presented in Appendix 2. Gauss-Seidel method is employed to solve the linear discretization equations. A computer code in FORTRAN language was developed, and the program flow chart is shown in Figure 3.

Before the analyses of the unsteady heat transfer and flow in the pipeline, the computer code was validated by field test data of a pipeline with a distance of 36 kilometers in China, which transported crude oil batches with 


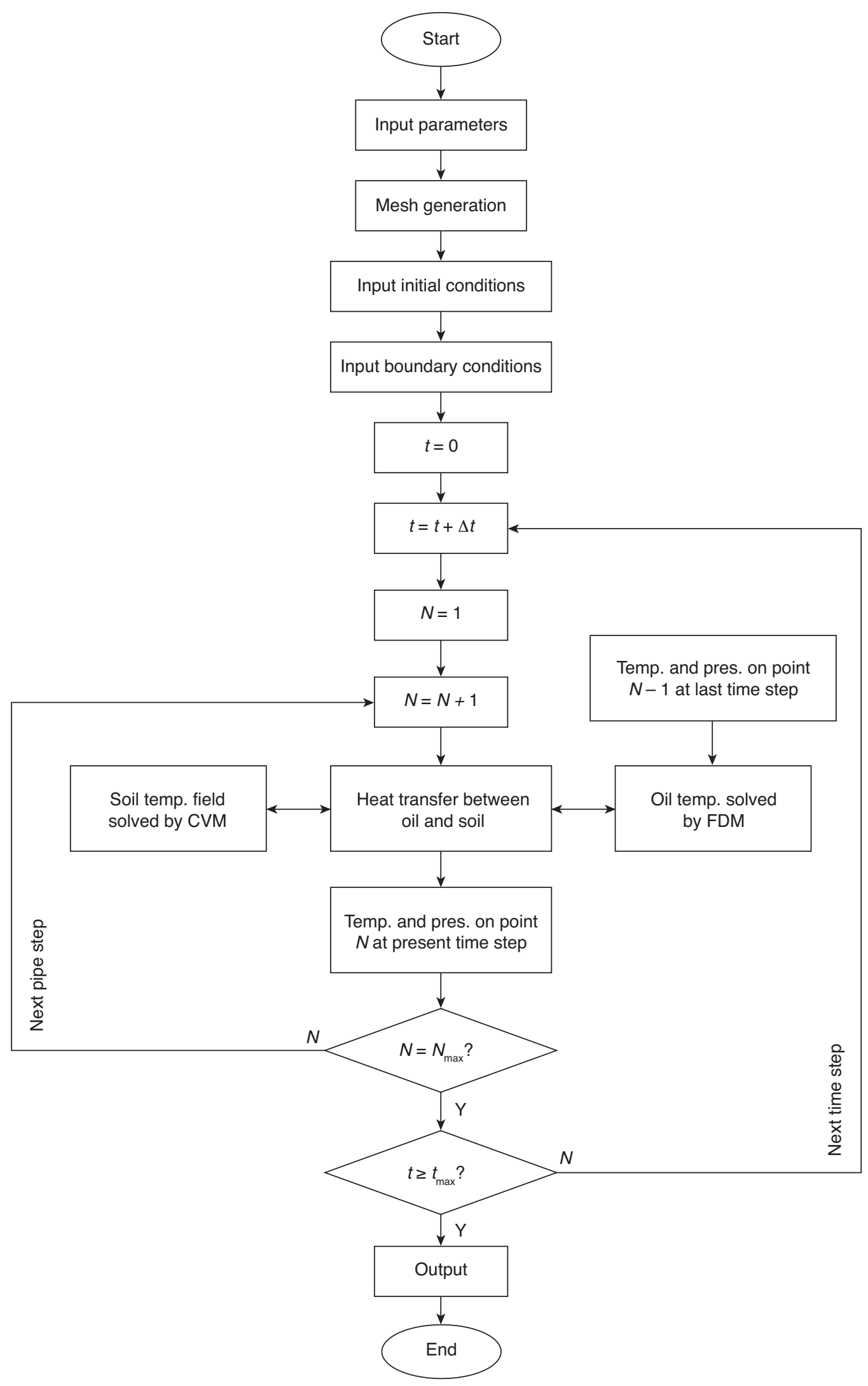

Figure 3

The flow of program. 
different inlet temperatures. During the tests, five oils were transported with different operating conditions listed in Table 2, including operating duration and the corresponding oil in the pipeline etc. The temperatures were measured with thermocouples having an accuracy of $0.5 \%$ ranging from 0 to $50{ }^{\circ} \mathrm{C}$. In the simulate calculation, the whole unstable process is divided into different cases with different time, different boundary conditions ("Inlet oil temperature" in $T a b .2$ ) and nearly consistent flow rate to simplify the complicated changing conditions and save the calculation time.

TABLE 2

Some experimental conditions

\begin{tabular}{l|c|c|c|c}
\hline Condition & Oils & $\begin{array}{c}\text { Operating } \\
\text { duration }(\mathrm{h})\end{array}$ & $\begin{array}{c}\text { Inlet oil } \\
\text { temperature }\left({ }^{\circ} \mathrm{C}\right)\end{array}$ & $\begin{array}{c}\text { Flow rate } \\
\left(\mathrm{m}^{3} / \mathrm{h}\right)\end{array}$ \\
\hline Steady state & A & $\backslash$ & 28 & 1000 \\
\hline Case 1 & B & 48 & 39 & 1450 \\
\hline Case 2 & B & 96 & 27 & 1450 \\
\hline Case 3 & C & 98 & 42 & 1330 \\
\hline Case 4 & C & 26 & 38 & 1040 \\
\hline Case 5 & D & 70 & 34 & 1000 \\
\hline Case 6 & D & 18 & 48 & 950 \\
\hline Case 7 & D & 78 & 43 & 950 \\
\hline Case 8 & B & 54 & 26 & 970 \\
\hline Case 9 & A & 40 & 30 & 990 \\
\hline Case 10 & A & 46 & 43 & 950 \\
\hline Case 11 & E & 80 & 48 & 980 \\
\hline
\end{tabular}

Figure 4 shows the comparison of the experimentally measured oil temperatures at the end of the pipeline with the numerical results. It is seen that the agreement is fairly good.

\section{THE THERMAL AND HYDRAULIC BEHAVIORS}

Our computer code is written for batch pipelining of various crude oils, and the second section has shown that it works well for five kinds of crude oils. For simplicity, batch pipelining of two kinds of crude oils, one of which is with high-pour-point and the other is with low-pourpoint, is studied to find out general thermal and hydraulic behaviors of the transport technique. Hereafter we call a crude oil with high-pour-point as CHPP and a crude oil with low-pour-point as CLPP for convenience.

We did a lot of samples by running our computer code with different operation parameters and similar thermal and hydraulic behaviors are gained. Herein one typical

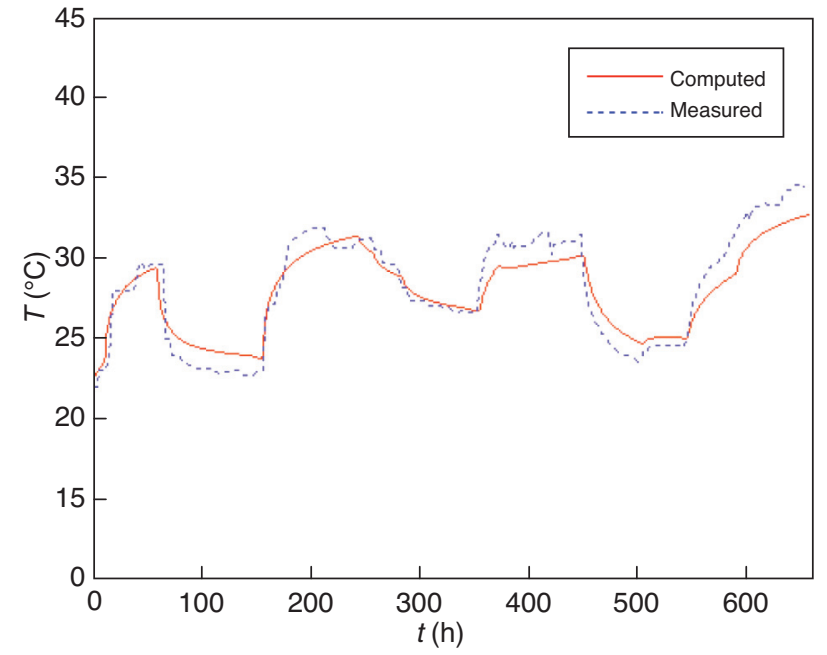

Figure 4

Comparison between the measured and computed oil temperatures at the end of pipeline.

case is presented, in which the main computational parameters are listed below: the annual throughput of the pipeline is $2 \times 10^{7} \mathrm{t} / \mathrm{a}$, half of which is CHPP and the rest is CLPP; the CHPP and CLPP are transported in the pipeline alternatively with a period of five days for each crude oil; $Z=48 ; R_{0}=0.342, R_{1}=0.352, R_{2}=0.360, R_{3}=0.372$; $H_{0}=1.8, H_{c}=10, L=10 ; T_{a}=-0.4, T_{c}=10 ; \lambda_{s}=1.4$, $\lambda_{1}=0.5, \lambda_{2}=48, \lambda_{3}=0.15 ; \rho_{s}=2225, \rho_{1}=800, \rho_{2}=7800$, $\rho_{3}=1000 ; C_{s}=1455, C_{1}=2000, C_{2}=1000, C_{3}=1800 ;$ $V_{a}=1 ; \beta=7.8 \times 10^{-4} ; g=9.8$; for CHPP, $\rho_{20}=857.9$, $c_{1}=8000, c_{2}=-0.2949, T_{p}=30, T_{n}=30$; for CLPP, $\rho_{20}=840.6, c_{1}=0.0218, c_{2}=-0.0545, T_{p}=0, T_{n}=15$.

According to the crude transport criteria in China, the temperature of the crude oil at the inlet of next station (from now on we call it oil outlet temperature for convenience) should not be lower than its pour point for safe operation. Comparing the normal temperature and the pour point of crude oils, and the temperatures of the surroundings, it is easy to reach from the heat transfer opinion that the CHPP has to be heated before being pushed into pipeline to satisfy the oil outlet temperature criterion. It is assumed that all the CHPP is heated to the same temperature. If transporting the CLPP without heating, it is apparent that the inlet temperature of CHPP must be high enough to reach the required outlet temperature. By running the code, it is found that the inlet temperature of CHPP should be not lower than $53^{\circ} \mathrm{C}$. The following quasi-steady results presented are those with CHPP inlet temperature at $53^{\circ} \mathrm{C}$ and independent of initial conditions. 


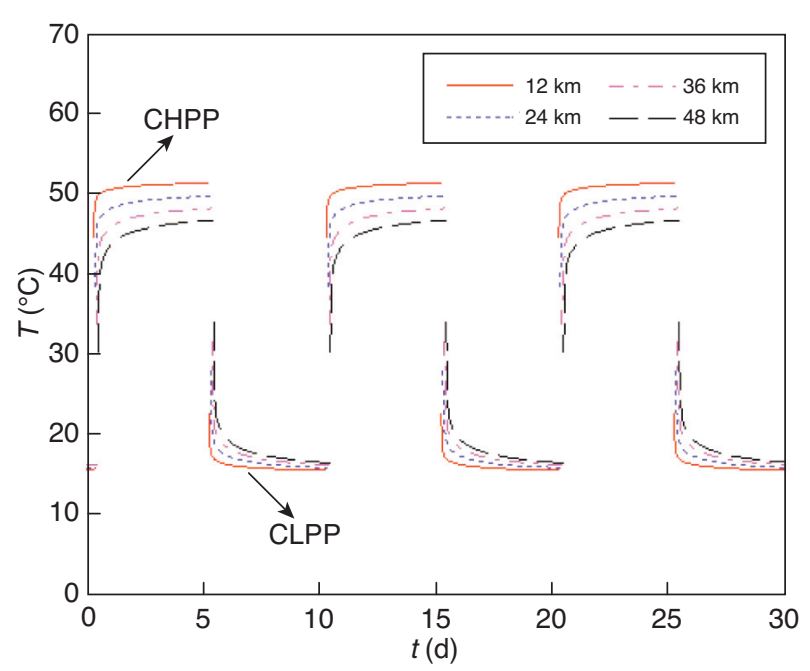

Figure 5

Periodic behavior of oil temperature at different axial pipeline positions.

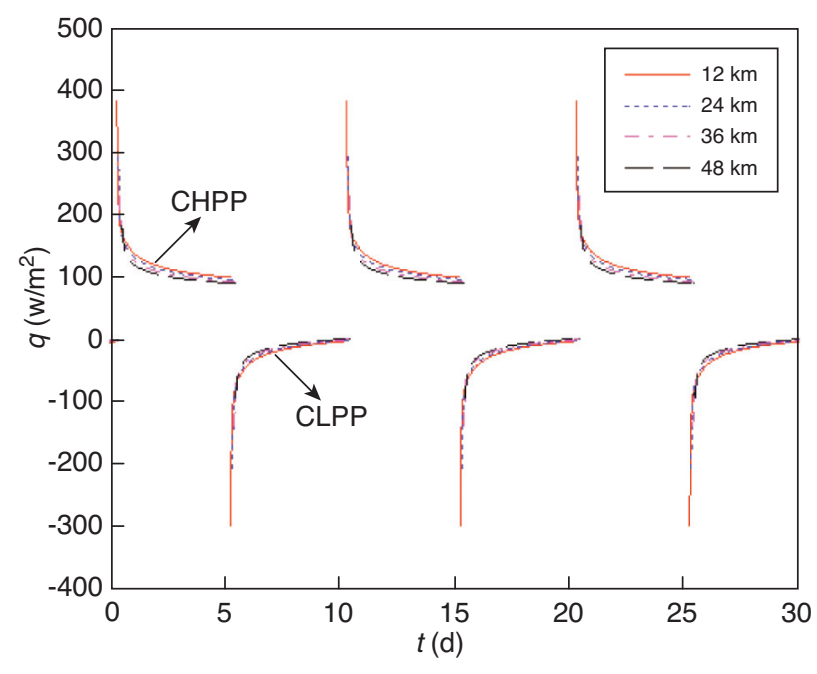

Figure 6

Heat flux density from the oil to the surroundings at different axial pipeline positions.

Figure 5 shows the variation of oil temperature versus time at different axial pipeline positions. It is apparent that CHPP with higher temperature and CLPP with lower temperature travel in the pipeline alternatively, periodic characteristic of six batches showing in Figure 5. In any batch at any axial position, the temperature of CHPP shows a similar behavior, which is the lowest at its start, increases with time and reaches the highest value at its end; and the contrary characteristics are for CLPP temperature. Note that there are sudden jumps of the oil

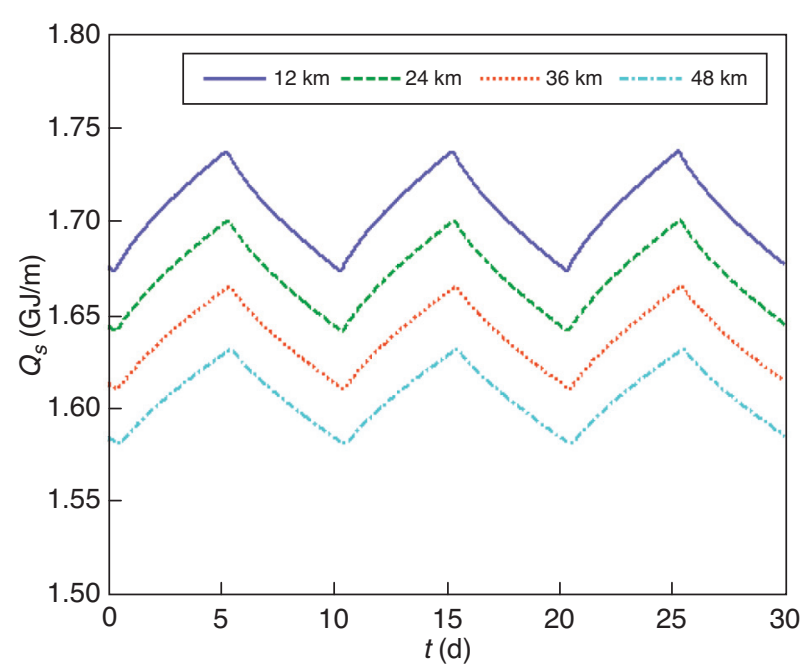

Figure 7

Heat storage of soil per unit length at different axial pipeline positions.

temperature at the interfaces of CHPP and CLPP, which is primarily due to assumption of the neglect of the mixture between two batches of crude oils.

Figure 6 shows the heat flux density from the oil to the surroundings, defined as $q=q_{1} / 2 \pi R_{0}$. The heat loss of the oil stream is defined as positive and the heat absorption of oil is defined as negative. From Figure 6 it is seen that the heat loss of CHPP is the largest at its start point and decreases as it flows down. Therefore, the temperature of CHPP is the lowest at its start and increases with time. For CLPP, the trend is just opposite.

The heat storage of soil per unit length is shown in Figure 7. The heat storage of soil increases as CHPP flows in and decreases as CLPP flows in. From Figure 7 it is seen that the surrounding soil is warmed greatly after the transport of CHPP for 5 days and has the largest amount of heat storage. When CLPP flows into the pipeline, it absorbs heat from the surrounding soil of higher temperature field heated by the previous passing CHPP. At the beginning part of CLPP, the soil having a larger amount of heat storage dissipates much heat to CLPP as shown in Figure 6 and makes the temperature of CLPP rising remarkably as shown in Figure 5. When more CLPP enters the pipeline, the heat storage of soil decreases as shown in Figure 7 and its capability of warming CLPP becomes smaller with time, making the temperature of CLPP decreasing compared to the start of CLPP continuously. At the end of CLPP, the heat storage of the soil is the smallest and so is the temperature of CLPP. Then CHPP flowing into the pipeline is greatly 


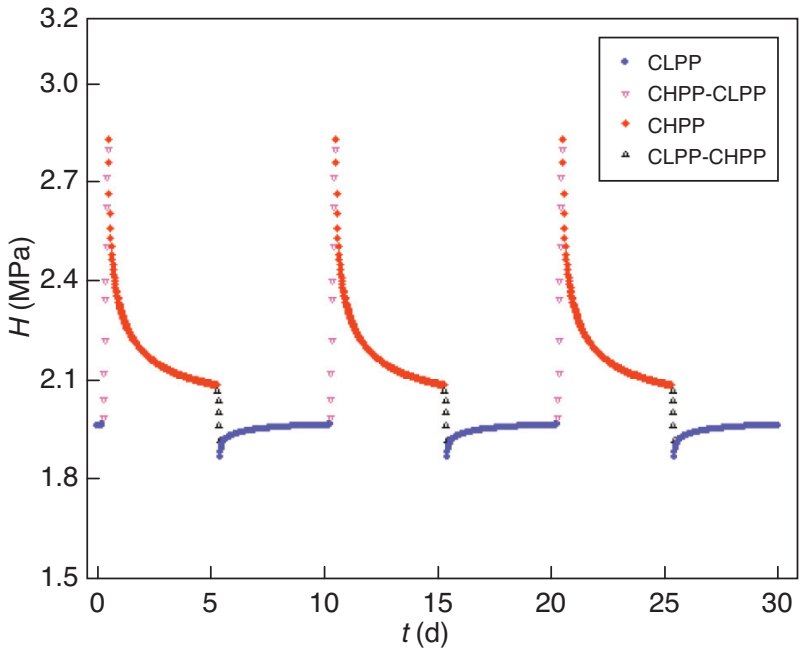

Figure 8

The periodic change of frictional loss.

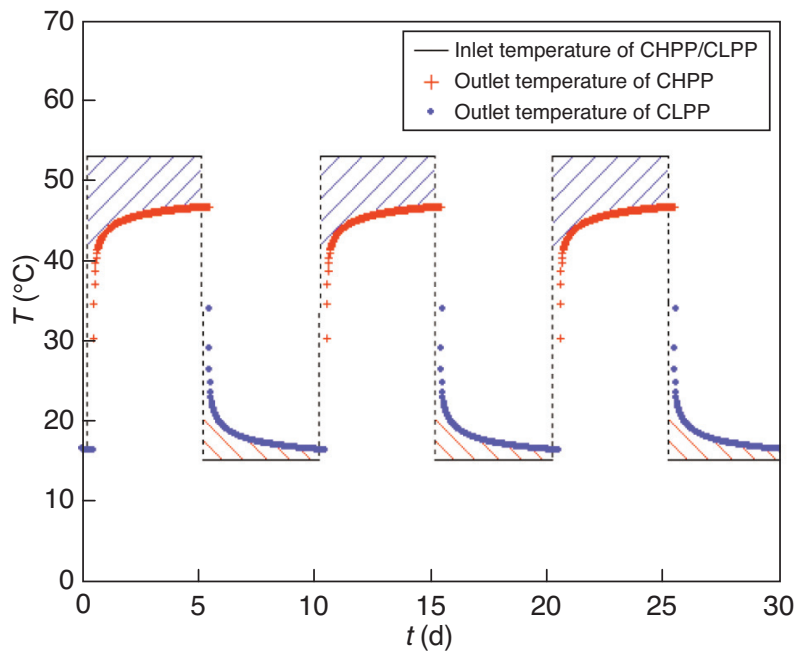

Figure 9

The inlet and outlet oil temperatures versus with time. cooled by the soil and the temperature drops sharply at its beginning part as shown in Figure 5. As more CHPP flows in, the soil is warmed gradually and CHPP temperature increases compared to its start at a fixed position.

Though at different positions the periodic behavior of temperature is the same, there is a "phase" lag of the temperature at downstream as compared to that of upstream. The lag time is the travel time of the oil taken from the upstream position to the downstream position. Along the pipeline, the temperature of CHPP decreases while that of CLPP increases with the increase of distance from the outlet of the preceding station, it is obvious that in the former process the soil absorbs heat from CHPP, resulting in a decrease of temperature of CHPP traveling in the pipeline and in the latter process the soils dissipated heat to CLPP, making a rise of CLPP temperature. Due to the decrease of CHPP temperature and increase of CLPP temperature along the pipeline, the amplitude of the temperature oscillation becomes smaller at larger axial position.

Figure 8 shows the frictional loss, due to the frictional drag, versus time with a large variation range, which can be divided into four regions, gradually decreasing region, sharply decreasing region, gradually increasing region and sharply increasing region. The large variation of frictional loss mainly stems from two reasons: one is that the viscosity of CHPP is larger than that of CLPP at the same temperature and the other is that both the viscosities of CHPP and CLPP decrease with temperature increasing. In the gradually decreasing region, only CHPP traveling in the pipeline, for the temperature of CHPP increases with time as shown in Figure 5, its viscosity decreases with time resulting in frictional loss decreases with time. On the other hand, in the gradually increasing region, only CLPP traveling in the pipeline, since its temperature decreases with time as shown in Figure 5, its viscosity increases with time and frictional loss increases with time. In the other two regions, CHPP and CLPP coexist in the pipeline. In the sharply increasing region, CHPP with larger-viscosity pushes CLPP with lower-viscosity forward and out of the pipeline, and the ratio of CHPP to the whole oils in the pipeline becomes larger and larger, resulting in a continuous increase of the frictional loss. In the sharply decreasing region, CLPP pushing CHPP forward and out of the pipeline, the frictional loss becomes smaller with time. The sharp increase and decrease of frictional loss is owing to the large change of viscosities of oils in the pipeline.

Figure 9 shows the inlet ( 0 kilometer) and outlet (48 kilometers) oil temperatures versus time. It is apparent that for CHPP the start point has the lowest temperature of $30.2^{\circ} \mathrm{C}$ and its end has the highest temperature of $46.6^{\circ} \mathrm{C}$, while for CLPP the start point has the highest temperature of $33.9^{\circ} \mathrm{C}$ and its end has the lowest temperature of $16.3^{\circ} \mathrm{C}$. According to the current oil outlet temperature criterion in the crude pipeline transport techniques in China, the temperature of the start point of CHPP and that of the end point of CLPP should be higher than their own pour point respectively. In this case the pour points for CHPP and CLPP are $30^{\circ} \mathrm{C}$ and $0^{\circ} \mathrm{C}$ respectively as stated 


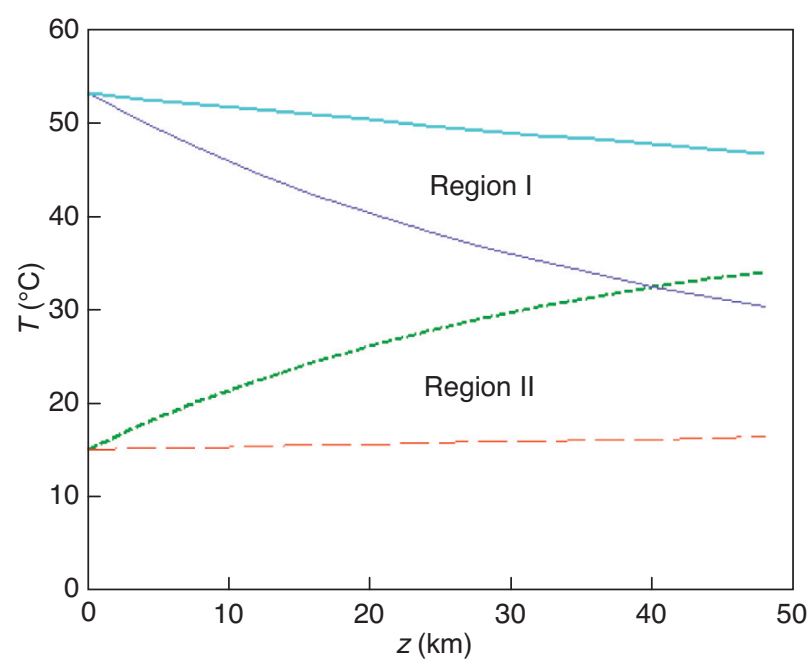

Figure 10

The maximum and minimum temperatures of CHPP and CLPP along the pipeline.

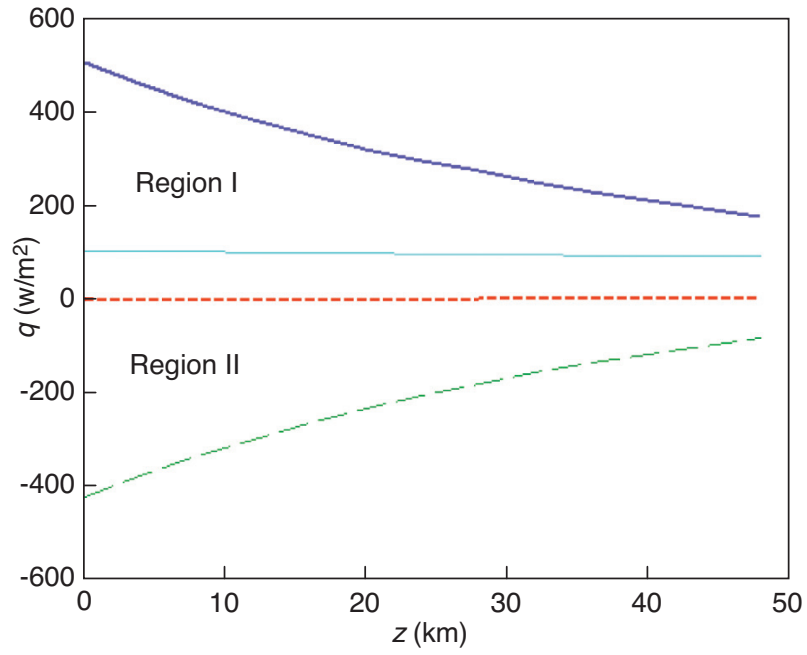

Figure 11

The maximum and minimum heat flux density along the pipeline. in the computational conditions. Therefore, the oil outlet temperature criterion is obviously satisfied, indicating the present heating scheme is appropriate. In six batches, the overall lost heat of CHPP is approximately proportional to the left twill areas and the overall heat absorbed by CLPP is approximately proportional to the right twill areas as shown in Figure 9. Obviously, the left twill areas are much larger than the right twill areas, indicating the heat lost by CHPP, most of which goes to the surroundings, is absorbed partly by CLPP.

Figure 5 shows for CHPP the temperature of the start point has a minimum value and its end has a maximum value while for CLPP the start point has a maximum value and its end has a minimum value. The maximum and minimum values of CHPP and CLPP along the pipelines are presented in Figure 10. The upper bold solid line represents the maximum temperature of CHPP, i.e., the temperature of the end point of CHPP, and the lower thin solid line represents the minimum temperature of CHPP, i.e. the temperature of the start point of CHPP. The upper bold dash line represents the maximum temperature of CLPP, i.e. the temperature of the start point of CLPP, and the lower thin dash line represents the minimum temperature of CLPP, i.e. the temperature of the end point of CLPP.

Figure 6 shows that CHPP dissipates the largest heat to the surroundings at its start point and the smallest heat at its end, while CLPP absorbs the largest heat at its start point and the smallest heat at its end. Figure 11 are the curves of the largest and the smallest values of heat flux densities from the oil to the surroundings along the pipelines, where solid lines are for CHPP and dash lines are for CLPP.

The temperature of the end point of CHPP decreases slightly as it travels in the pipeline, actually from $53^{\circ} \mathrm{C}$ to $46.6^{\circ} \mathrm{C}$, while the temperature of its start point decreases apparently from $53^{\circ} \mathrm{C}$ to $30.2^{\circ} \mathrm{C}$ as shown Figure 10 . The start point of CHPP experiences a quicker drop of temperature at the beginning and a slower temperature drop as it flows down, and herein the quicker and then slower drop is caused by the larger and then smaller heat loss as indicated by the bold solid line in Figure 11. Figure 10 shows the temperature of the end point of CHPP drops almost linearly, which is owing to the almost constant heat loss as indicated by the thin solid line in Figure 11. For CLPP, the temperature variation characteristics are just opposite, i.e. the temperature of the start point of CLPP has an obvious increase as it travels in the pipeline, actually from $15^{\circ} \mathrm{C}$ to $33.9^{\circ} \mathrm{C}$, while the temperature of its end point increases only $1.3^{\circ} \mathrm{C}$. The start point of CLPP experiences a quicker rise of temperature at the beginning and a slower rise as it flows down. The quicker and then slower rise is due to the larger and then smaller heat absorption as indicated by the thin dash line shown in Figure 11. The temperature of the end point of CLPP increases almost linearly and slowly, which is owing to almost constant and small heat absorption as indicated by the bold dash line in Figure 11. In summary, at the beginning of the pipeline there are larger temperature 
differences between the soil and the crude oils, resulting in stronger heat transfer, therefore a quick rise or drop of temperature of the crude oil.

Apparently from Figure 10, Region I between the upper and lower solid lines is the variation range of the CHPP temperature along the pipeline while the variation range of the CLPP temperature along the pipeline is between the upper and lower dash lines, Region II as shown. Since both the maximum and minimum temperatures decreases along the pipeline, the shape of Region I looks like a downward open mouth of a crocodile while that of Region II has a shape like an upward open mouth of a crocodile. With the increase of the distance from the outlet of the preceding station, the variation ranges of the temperature for both CHPP and CLPP become wider. Why the variation range of temperature becomes wider? We take CHPP as an example to explain it. The reason is that the temperature drop of the start point of CHPP is always quicker than that of the end point of CHPP at any axial pipeline position.

We note an interesting phenomenon that the temperature of the start point of CLPP is higher than that of start point of CHPP after 40 kilometers from the outlet of preceding station. This is due to the strong heat loss of the start point of CHPP to the long-time cooled soil and the strong heat absorption of the start point of CLPP from the long-time warmed soil.

\section{ECONOMIC ANALYSIS AND FLOW SAFETY STUDY}

Based on the analyses of the hydraulic and thermal behaviors in Section 3, economical analysis, which is always a crucial problem in pipeline management, is carried out in this section. For simplicity in this study we do not consider the energy required by pumping and focus on the heating energy. Generally speaking the higher the inlet temperature, the more energy will be consumed for heating. Therefore the inlet temperature of oil is a key parameter in economical evaluation. After careful consideration, three heating schemes are proposed and evaluated, and the operation parameters are the same as those in Section 3 except the inlet temperatures:

- CHPP is heated to a uniform temperature before entering a pipeline and CLPP is transported without heating or heated to a lower temperature than that of CHPP. In Section 3 we adopt this kind of heating scheme;

- Both CLPP and CHPP are heated to the same inlet temperature before flowing into the pipeline;

- Only a small portion of CLPP traveling before CHPP is heated while all CHPP is heated to a uniform temperature. The inlet temperature of the heated CLPP can be either higher or lower than that of CHPP. For simplicity in this study it is assumed to be the same as that of CHPP and only 20 percent CLPP is heated.

By running the code, the minimum inlet temperatures satisfying the oil outlet temperature criterion are obtained as shown in Table 3.

TABLE 3

Inlet temperatures of different heating schemes

\begin{tabular}{c|c|c}
\hline Heating schemes & $\mathrm{CHPP}\left({ }^{\circ} \mathrm{C}\right)$ & $\operatorname{CLPP}\left({ }^{\circ} \mathrm{C}\right)$ \\
\hline$(1)$ & 53 & 15 \\
\hline$(2)$ & 32 & 32 \\
\hline$(3)$ & 34 & $20 \%: 34 ; 80 \%: 15$ \\
\hline
\end{tabular}

The energy consumed by heating can be calculated by $\int_{0}^{t^{\prime}} c(t) \rho(t) A V(t)\left[T_{\text {inlet }}(t)-T_{0}(t)\right] \mathrm{d} t$, in which $t^{\prime}$ represents a period time of 30 days. The energy consumed by different heating schemes is presented in Figure 12. As can be seen from it, the first heating scheme consumes the most heat energy and the third one consumes the least heat energy, which is only $33.9 \%$ of the first one. From the aspect of economy, the third heating scheme is a promising method of batch pipelining. However, it should be noted that the heating proportion is chosen as $20 \%$, which is optional and not necessarily the most economical; how to determine the most economical heating portion is still a problem in economical analysis and needs a further study [11].

As we know, the economy of heating scheme has something to do with the average oil outlet temperature.

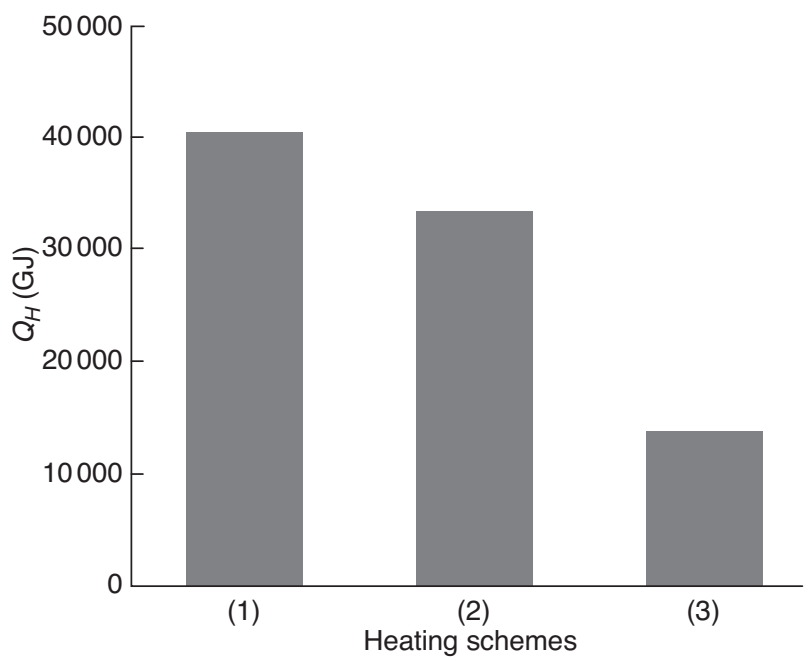

Figure 12

Heat energy consumptions of different heating schemes. 


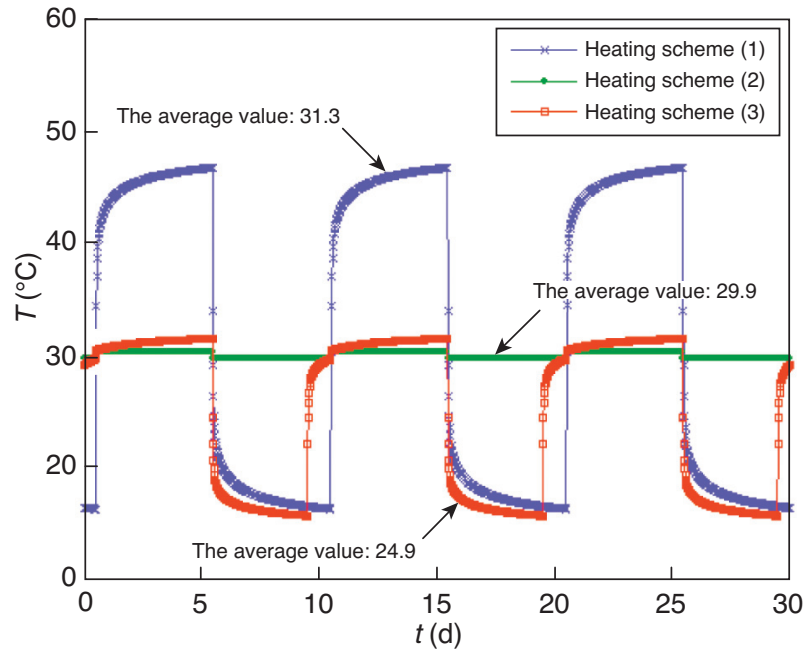

Figure 13

Outlet temperatures of different heating schemes.

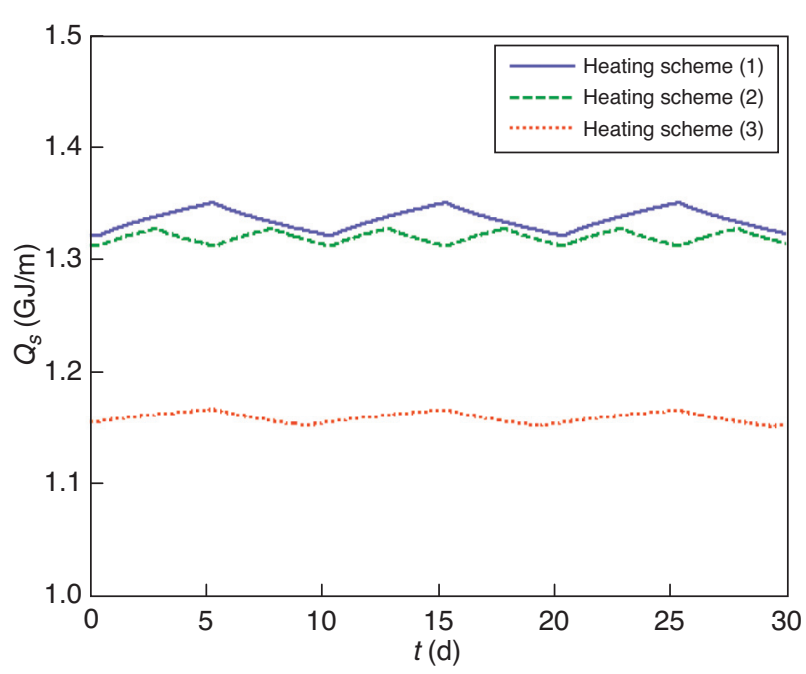

Figure 14

Soil heat storage at the midpoint of the pipeline.
The lower the average outlet temperature is, the lesser the heat energy consumption will be. Specifically, the outlet temperatures of different heating schemes are shown in Figure 13. As can be seen from it, the three heating schemes are all feasible because all the lowest outlet temperatures of CHPP are not lower than $30^{\circ} \mathrm{C}$. The average outlet temperature of the first scheme is the highest among the three ones while that of the third scheme is the lowest. It should be noted that, in the second heating scheme, there is still some difference between the outlet temperatures of the two kinds of crude oils although their inlet temperatures are the same. This is mainly because of the higher viscosity of CHPP than that of CLPP at the transporting temperatures; therefore, the frictional heat of the transporting process is more than that of CLPP and its outlet temperature is higher.

Safety is another important issue in batch pipelining of different crude oils. Restart of a pipeline after its shutdown due to routine examinations or unexpected accidents is always an important problem to be considered seriously. If the pipeline experiences a sharp temperature decrease during shutdown, the poor flow ability of CHPP at low temperature may result in difficulties of restart. Therefore, the economical analyses should be based on the flow safety of the crude oils. Which scheme is the most safety in the proposed three heating schemes? It is obvious that higher soil heat storage will upgrade the safety of the pipeline during the shutdown. Figure 14 shows the heat storage at the midpoint of the pipeline versus time. It is seen clearly that the heat storage of the first scheme is the largest and therefore most safely.

\section{CONCLUSIONS}

The thermal and hydraulic behaviors of batch pipelining of different crude oils are studied numerically. The periodic behaviors of heat flux density, oil temperature, heat storage of soil and frictional loss are presented and explained, the strong coupling relations within them are clarified. Three heating schemes are proposed and the economy and safety are preliminarily evaluated, and we find that the heating scheme, in which only a small portion of CLPP just traveling before CHPP is heated and all CHPP is heated to a uniform temperature, costs the smallest heating energy.

\section{ACKNOWLEDGMENTS}

This work was supported by the National Natural Science Foundation of China (No. 50876114 and No. 50506017), SRF for ROCS, SEM and National High-tech R\&D Program of China (No. 2006AA09Z357).

\section{REFERENCES}

1 Mecham T., Wikerson B., Templeton B. (2000) Full Integration of SCADA, Field Control Systems and High Speed Hydraulic Models-Application Pacific Pipeline System, International Pipeline Conference, Calgary, Alberta, Canada, October 1-5.

2 Cui X.G. (2005) Analysis of transient hydraulic-thermal interaction during cool and hot oil batch pipelining and its applications, $P h D$ thesis, China University of Petroleum, Beijing. 
3 Fan H.C. (2005) Research on cool and hot oil batch pipelining, Master's thesis, China University of Petroleum, Beijing.

4 Yao F. (2006) Study on the cool and hot oil batch transporting schemes of West Crude Pipe, Master's thesis, China University of Petroleum, Beijing.

5 Cui X.G., Zhang J.J. (2004) Determination of the thermal influence zone of buried hot oil pipeline on steady operation, $J$. Univ. Petrol. (Ed. Nat. Sci.) 28, 2, 75-78.

6 Cui H. (2006) Numerical simulation of thermodynamically transient scenarios for a hot oil pipeline, $P h D$ thesis, China University of Petroleum, Beijing.

7 Zhao Z.N. (2002) Heat Transfer, Higher Education Press, Beijing.
8 Yang X.H. (2006) Design and Management of Oil Pipelines, China University of Petroleum Press, Dongying.

9 Tao W.Q. (2002) Numerical Heat Transfer, 2nd ed., Xi'an Jiaotong University Press, Xi'an.

10 Tao W.Q. (2000) Recent advances of numerical heat transfer, Science Press, Beijing.

11 Wang K., Zhang J.J., Yu B. (2008) Optimal heating ratio of batch pipelining of cold and hot crude oils, J. China Univ. Petrol. (Ed.Nat.Sci.) 32, 5, 102-107.

Final manuscript received in November 2008 Published online in July 2009 


\section{APPENDIX 1}

$$
\begin{gathered}
\frac{\partial}{\partial t}(\rho A)+\frac{\partial}{\partial z}(\rho V A)=0 \\
\frac{\partial V}{\partial t}+V \frac{\partial V}{\partial z}=-g \sin \alpha-\rho \frac{\partial p}{\partial z}-\frac{f}{D} \frac{V^{2}}{2} \\
\frac{\partial}{\partial t}\left[(\rho A)\left(u+\frac{V^{2}}{2}+g s\right)\right]+\frac{\partial}{\partial z}\left[(\rho V A)\left(h+\frac{V^{2}}{2}+g s\right)\right]=-\pi D q
\end{gathered}
$$

Substituting $u=h-\frac{P}{\rho}$ to Equation (A-3), the following equation is obtained:

$$
\begin{aligned}
& \frac{\partial}{\partial t}\left(\rho A h-P A+\frac{\rho V^{2} A}{2}+\rho g S A\right)+\frac{\partial}{\partial z}\left(\rho V A h+\frac{\rho V^{3} A}{2}+\rho g S V A\right)+D q=0 \\
& h\left[\frac{\partial(\rho A)}{\partial t}+\frac{\partial(\rho V A)}{\partial z}\right]+\rho A \frac{\partial h}{\partial t}-\frac{\partial(P A)}{\partial t}+\frac{V^{2}}{2}\left[\frac{\partial(\rho A)}{\partial t}+\frac{\partial(\rho V A)}{\partial z}\right]+\rho V A \frac{\partial V}{\partial t} \\
& +g S\left[\frac{\partial(\rho A)}{\partial t}+\frac{\partial(\rho V A)}{\partial z}\right]+\rho V A \frac{\partial h}{\partial z}+\rho V^{2} A \frac{\partial V}{\partial z}+\rho V A g \frac{\partial s}{\partial z}+\pi D q=0
\end{aligned}
$$

Substituting Equation (A-1) to Equation (A-5) and simplified:

$$
\begin{gathered}
\rho A \frac{\partial h}{\partial t}-\frac{\partial(P A)}{\partial t}+\rho V A \frac{\partial V}{\partial t}+\rho V A \frac{\partial h}{\partial z}+\rho V^{2} A \frac{\partial V}{\partial z}+\rho V A g \frac{\partial s}{\partial z}+\pi D q=0 \\
\rho A\left(\frac{\partial h}{\partial t}+V \frac{\partial h}{\partial z}\right)-\frac{\partial(P A)}{\partial t}+\rho V A\left(\frac{\partial V}{\partial t}+V \frac{\partial V}{\partial z}\right)+\rho V A g \frac{\partial s}{\partial z}+\pi D q=0
\end{gathered}
$$

Substituting Equation (A-2) to Equation (A-7) and simplified:

$$
\left(\frac{\partial h}{\partial t}+V \frac{\partial h}{\partial z}\right)-\frac{1}{\rho}\left(\frac{\partial P}{\partial t}+V \frac{\partial P}{\partial z}\right)-\frac{f V^{3}}{2 D}+\frac{4 q}{\rho D}=0
$$

Substituting:

$$
\frac{\mathrm{d} h}{\mathrm{~d} t}=\frac{\partial h}{\partial z} \frac{\mathrm{d} z}{\mathrm{~d} t}+\frac{\partial h}{\partial t}, \frac{\mathrm{d} P}{\mathrm{~d} t}=\frac{\partial P}{\partial z} \frac{\mathrm{d} z}{\mathrm{~d} t}+\frac{\partial P}{\partial t}
$$

to Equation (A-8), and we can get the total differential heat equation of the oil:

$$
\frac{\mathrm{d} h}{\mathrm{~d} t}-\frac{1}{\rho} \frac{\mathrm{d} P}{\mathrm{~d} t}-\frac{f V^{3}}{2 D}+\frac{4 q}{\rho D}=0
$$


From:

$$
\mathrm{d} h=C_{p} \mathrm{~d} T+\left[v-(T+273.15)\left(\frac{\partial v}{\partial T}\right)_{P}\right] \mathrm{d} P, \text { we can get } \frac{\mathrm{d} h}{\mathrm{~d} t}=C_{p} \frac{\mathrm{d} T}{\mathrm{~d} t}+\left[v-(T+273.15)\left(\frac{\partial v}{\partial T}\right)_{P}\right] \frac{\mathrm{d} P}{\mathrm{~d} t}
$$

while substituting it to Equation (A-9), the following equation is obtained:

$$
C_{P} \frac{\mathrm{d} T}{\mathrm{~d} t}-\frac{T+273.15}{\rho} \beta \frac{\mathrm{d} P}{\mathrm{~d} t}-\frac{f V^{3}}{2 D}+\frac{4 q}{\rho D}=0
$$

Substituting $\left(\frac{\partial v}{\partial T}\right)_{P}=\beta v=\frac{\beta}{\rho}$ to Equation (A-10), the heat transfer equation of the pipe flow is obtained:

$$
C_{P} \frac{\mathrm{d} T}{\mathrm{~d} t}-\frac{T+273.15}{\rho} \beta \frac{\mathrm{d} P}{\mathrm{~d} t}-\frac{f V^{3}}{2 D}+\frac{4 q}{\rho D}=0
$$

where the volume expansion coefficient $\beta$ is defined by:

$$
\beta=\left(\frac{\frac{\Delta v}{v}}{\Delta T}\right)_{P}
$$




\section{APPENDIX 2}

- Discretion of the heat transfer equation of the pipe flow

The pipeline is divided into several computing segments, as shown in Figure 2c. Equation (4) is discreted by finite difference method in the time interval $\Delta$ :

$$
C_{p}\left(\frac{T_{i}-T_{i}^{0}}{\Delta t}+\frac{T_{i}^{0}-T_{i-1}^{0}}{\Delta z} V_{i}\right)-\frac{T_{i}}{\rho} \beta\left(\frac{p_{i}-p_{i}^{0}}{\Delta t}+\frac{p_{i}^{0}-p_{i-1}^{0}}{\Delta z} V_{i}\right)-\frac{f V_{i}^{3}}{2 D}=-\frac{4 q_{i}}{\rho D}
$$

From Equation (A-13), we can get:

$$
T_{i}=\frac{\frac{f V_{i}^{3}}{2 D}-\frac{4 q_{i}}{\rho D}-C_{p} \frac{T_{i}^{0}-T_{i-1}^{0}}{\Delta z} V_{i}+\frac{C_{p} T_{i}^{0}}{\Delta t}}{\frac{C_{p}}{\Delta t}-\frac{\beta}{\rho}\left(\frac{p_{i}-p_{i}^{0}}{\Delta t}+\frac{p_{i}-p_{i-1}}{\Delta z} V_{i}\right)}
$$

- Discretion of the heat conduct equations of soil, wax layer, pipe wall and corrosion protection layer.

Figure A-1

Control volume of the triangle.

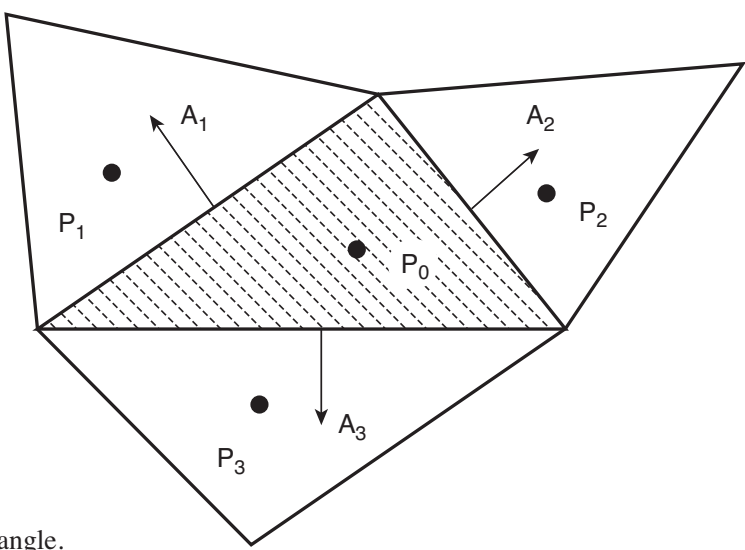

Put the computing node in the gravity center of the triangle, shown in Figure A-1, the node $\mathrm{P}_{0}$ can be seen as a represent of the triangle area with shade line. According to the finite volume method, the triangle is called the control volume of $\mathrm{P}_{0}$. Discreting the heat conduct equation is to set up the relation between the temperature of node $\mathrm{P}_{0}$ and the temperatures of its adjacent points $\mathrm{P}_{1}-\mathrm{P}_{3}$. To discrete conveniently, the conduct equation can be written as the integrating form for a random control volume:

$$
\int_{V} \frac{\partial T_{s}}{\partial t} \mathrm{~d} V=\int_{A} \frac{\lambda_{s}}{\rho_{s} c_{s}} \nabla T_{s} \cdot \mathrm{d} A
$$

where ' $V$ ' is the capacity of the control volume (for a two dimensional problem, it is the area of the control volume), ' $A$ ' is the area vector of the control volume interface and its forward direction is the same as the unit vector of the outward normal, as shown in Figure A-1. Signal '.' represents the inner product of two vectors. Applying Equation (A-15) to the triangle's control volume shown in Figure A-1 obtains the following equation:

$$
\frac{T_{s p_{0}}-T_{s p_{0}}^{0}}{\Delta t} A_{P_{0}}=\frac{\lambda_{s}}{\rho_{s} c} \sum_{s=1}^{3}\left(\nabla T_{s}\right)_{j} \cdot A_{j}
$$

where $A_{P 0}$ is the triangle's area whose gravity center is $\mathrm{P}_{0} ; T_{s p 0}$ and $T_{p 0}^{0}$ is the temperature value of $\mathrm{P}_{0}$ at present time layer and the previous time layer at time interval $\Delta t$, respectively; $\left(\nabla T_{s}\right)_{j}$ is the average temperature gradient of interface 1,2,3, which can be calculated by the liner interpolation of the temperatures on the nodes:

$$
\left(\nabla T_{s}\right)_{j}=\omega_{P_{0}}\left(\nabla T_{s}\right)_{P_{0}}+\omega_{P_{j}}\left(\nabla T_{s}\right)_{P_{j}}
$$

where $\omega_{P 0}$ and $\omega_{P j}$ are interpolation factors. 
As can be seen from the above derivation, once the temperature gradient of the nodes is known, the discretion equation is determined. The temperature gradient $\left(\nabla T_{s}\right)_{P 0}$ can be calculated using the least square method:

$$
\frac{\partial}{\partial\left(\nabla T_{s}\right)_{P_{0}}^{i}} \sum_{j=1}^{3} \frac{1}{\left|d_{j}\right|}\left\{\frac{T_{s P_{j}}-T_{s P_{0}}}{\left|d_{j}\right|}-\left(\nabla T_{s}\right)_{P_{0}} \frac{d_{j}}{\left|d_{j}\right|}\right\}^{2}=0, i=1,2
$$

where $\left(\nabla T_{s}\right)_{P 0}^{i}$ is the component of temperature gradient of $\mathrm{P}_{0}$ at axis $j ; d_{j}$ is the directed line segment from $\mathrm{P}_{0}$ to $\mathrm{P}_{j}$.

Equation (A-18) can be expressed with matrix:

$$
\left(\nabla T_{s}\right)_{P_{0}}=G^{-1} h^{\prime}
$$

The four components of the matrix $G$ and the two components of the row vector are defined by:

$$
\begin{gathered}
g_{k l}=\sum_{j=1}^{3} \frac{d_{j}^{k} \times d_{j}^{l}}{\left|d_{j}\right|^{3}} \quad k=l=1,2 \\
h_{k}^{\prime}=\sum_{j=1}^{3} \frac{T_{s P_{j}}-T_{s P_{o}}}{\left|d_{j}\right|} \cdot \frac{d_{j}^{k}}{\left|d_{j}\right|^{2}} \quad k=1,2
\end{gathered}
$$

where $d_{j}^{k}$ is the $k$ th component of vector $d_{j}$. Once the temperature gradient of the node is solved, the temperature gradient on the interface can be obtained easily using Equation (A-17). The losing couple problem will appear if directly using Equation (A-17), so we can use the explicit revise method to modify it:

$$
\begin{aligned}
& \left(\nabla T_{s}\right)_{j}=\left(\omega_{P_{o}}\left(\nabla T_{s}\right)_{P_{o}}+\omega_{P_{j}}\left(\nabla T_{s}\right)_{P_{j}}\right) \\
& \times\left(1-\frac{d_{j}}{\left|d_{j}\right|} \frac{d_{j}}{\left|d_{j}\right|}\right)+\frac{T_{s P_{j}}-T_{s P_{o}}}{\left|d_{j}\right|} \frac{d_{j}}{\left|d_{j}\right|}
\end{aligned}
$$

Equation (A-21) together with Equation (A-16) gives the discretion equation:

$$
\begin{aligned}
& a_{p_{0}} T_{s p_{o}}=\sum_{j=1}^{3} a_{p_{j}} T_{s p_{j}}+b \\
& a_{p_{j}}=\frac{\lambda_{s}}{\rho_{s} c_{s}} \frac{d_{j} \cdot A_{j}}{\left|d_{j}\right|^{2}} \quad i=1,2,3 \\
& a_{p_{o}}=\sum_{j=1}^{3} a_{p_{j}}+\frac{A_{P_{0}}}{\Delta t} \\
& b=\frac{T_{s p_{0}}^{0} A_{P_{0}}}{\Delta t}+\frac{\lambda_{s}}{\rho_{s} c_{s}} \sum_{j=1}^{3}\left(\omega_{P_{o}}\left(\nabla T_{s}\right)_{P_{0}}+\omega_{P_{j}}\left(\nabla T_{s}\right)_{P_{j}}\right)\left(1-\frac{d_{j}}{\left|d_{j}\right|} \frac{d_{j}}{\left|d_{j}\right|}\right)
\end{aligned}
$$

Conduct equations of the wax layer, pipe wall and the corrosion protection layer are given by:

$$
\rho_{k} c_{k} \frac{\partial T_{k}}{\partial t}=\frac{1}{r} \frac{\partial}{\partial r}\left(r \lambda_{k} \frac{\partial T_{k}}{\partial r}\right)+\frac{1}{r} \frac{\partial}{\partial \theta}\left(\frac{\lambda_{k}}{r} \frac{\partial T_{k}}{\partial \theta}\right)
$$

Integrating Equation (A-23) in the control volume shown in Figure A-2:

$$
\begin{aligned}
& \int_{t}^{t+\Delta t} \int_{s}^{n} \int_{w}^{e} r \rho_{k} c_{k} \frac{\partial T_{k}}{\partial t} \mathrm{~d} \theta \mathrm{d} r \mathrm{~d} t= \\
& \int_{t}^{t+\Delta t} \int_{s}^{n} \int_{w}^{e} \partial\left(r \lambda_{k} \frac{\partial T_{k}}{\partial r}\right) \mathrm{d} \theta \mathrm{d} t+\int_{t}^{t+\Delta t} \int_{s}^{n} \int_{w}^{e} \partial\left(\frac{\lambda_{k}}{r} \frac{\partial T_{k}}{\partial \theta}\right) \mathrm{d} r \mathrm{~d} t
\end{aligned}
$$


Figure A-2

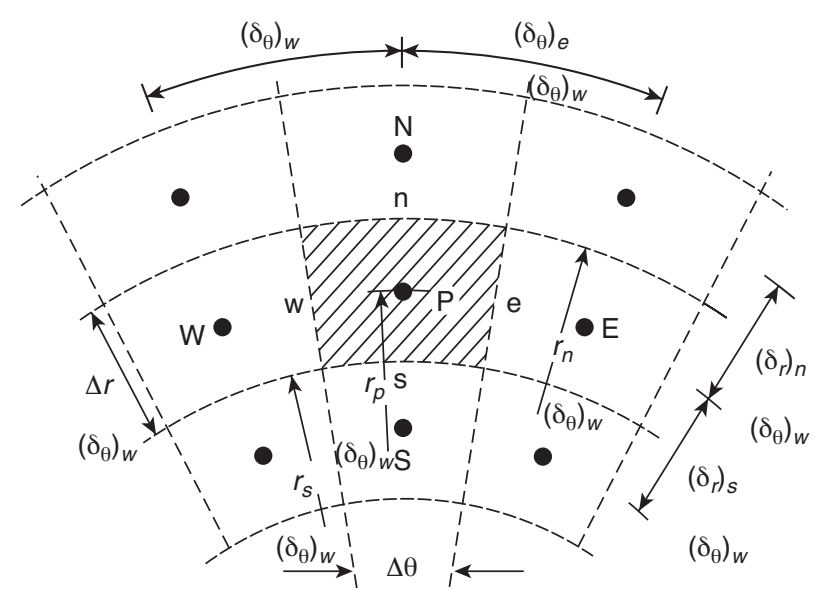

The girding system in the polar coordinates

$$
\begin{aligned}
& \left(\rho_{k} c_{k}\right)_{P}\left(T_{k P}-T_{k P}^{0}\right) \frac{r_{n}+r_{s}}{2} \Delta r \Delta \theta= \\
& {\left[r_{n} \lambda_{k n} \frac{T_{k N}-T_{k P}}{(\delta r)_{n}}-r_{s} \lambda_{k s} \frac{T_{k P}-T_{k S}}{(\delta r)_{s}}\right] \Delta \theta \Delta t+\left[\frac{\lambda_{k e}}{r_{e}} \frac{T_{k E}-T_{k P}}{(\delta \theta)_{e}}-\frac{\lambda_{k w}}{r_{w}} \frac{T_{k P}-T_{k W}}{(\delta \theta)_{w}}\right] \Delta r \Delta t} \\
& \left(\rho_{k} c_{k}\right)_{P}\left(T_{k P}-T_{k P}^{0}\right) \frac{r_{n}+r_{s}}{2} \Delta r \Delta \theta= \\
& -\left[\frac{r_{n} \lambda_{k n}}{(\delta r)_{n}} \Delta \theta \Delta t+\frac{r_{s} \lambda_{k s}}{(\delta r)_{s}} \Delta \theta \Delta t+\frac{\lambda_{k e}}{r_{e}(\delta \theta)_{e}} \Delta r \Delta t+\frac{\lambda_{k w}}{r_{w}(\delta \theta)_{w}} \Delta r \Delta t\right] T_{k P} \\
& +\frac{r_{n} \lambda_{k n}}{(\delta r)_{n}} \Delta \theta \Delta t T_{k N}+\frac{r_{s} \lambda_{k s}}{(\delta r)_{s}} \Delta \theta \Delta t T_{k S}+\frac{\lambda_{k e}}{r_{e}(\delta \theta)_{e}} \Delta r \Delta t T_{k E}+\frac{\lambda_{k w}}{r_{w}(\delta \theta)_{w}} \Delta r \Delta t T_{k W} \\
& \quad-\left(\rho_{k} c_{k}\right)_{P}\left(T_{k P}-T_{k P}^{0}\right) \frac{\left(r_{n}+r_{s}\right)}{2 \Delta t} \Delta r \Delta \theta= \\
& \quad\left[\frac{r_{n} \lambda_{k n}}{(\delta r)_{n}} \Delta \theta+\frac{r_{s} \lambda_{k s}}{(\delta r)_{s}} \Delta \theta+\frac{\lambda_{k e}}{r_{e}(\delta \theta)_{e}} \Delta r+\frac{\lambda_{k w}}{r_{w}(\delta \theta)_{w}} \Delta r T_{k P}\right. \\
& \quad-\frac{r_{n} \lambda_{k n}}{(\delta r)_{n}} \Delta \theta T_{k N}-\frac{r_{s} \lambda_{k s}}{(\delta r)_{s}} \Delta \theta T_{k S}-\frac{\lambda_{k e}}{r_{e}(\delta \theta)_{e}} \Delta r T_{k E}-\frac{\lambda_{k w}}{r_{w}(\delta \theta)_{w}} \Delta r T_{k W}
\end{aligned}
$$

$$
a_{P} T_{k P}=a_{E} T_{k E}+a_{W} T_{k W}+a_{N} T_{k N}+a_{S} T_{k S}+b
$$

where:

$$
\begin{aligned}
& a_{E}=\frac{\Delta r}{r_{e}(\delta \theta)_{e} / \lambda_{k e}}, a_{W}=\frac{\Delta r}{r_{w}(\delta \theta)_{w} / \lambda_{k w}}, a_{N}=\frac{r_{n} \Delta \theta}{(\delta r)_{n} / \lambda_{k n}}, a_{S}=\frac{r_{s} \Delta \theta}{(\delta r)_{s} / \lambda_{k s}}, \\
& a_{P}^{0}=\frac{0.5\left(\rho_{k} c_{k}\right)_{P}\left(r_{n}+r_{s}\right) \Delta r \Delta \theta}{\Delta t}, a_{P}=a_{E}+a_{W}+a_{N}+a_{S}+a_{P}^{0}, b=a_{P}^{0} T_{k P}^{0}
\end{aligned}
$$

Using Gauss-Seidel method, conjugate gradient method, etc. to solve Equation (A-22) and Equation (A-28), we can get the temperature on each node. If the grid is dense enough, the temperatures on the nodes can be seen as the soil temperature field. 